Public-health policy regarding beriberi, as Carpenter reminds readers, is more than a matter of historical interest. In the 1980s Australian health policy-makers debated the utility of 'enriching' beer and other alcoholic beverages with thiamine as a means of increasing the thiamine intake of chronic alcoholics. Amid resistance from both the brewing industry and temperance organizations (who feared beer would be advertised as a health food), these plans were scrapped in favour of augmenting flour and bread. Here and throughout the book, Carpenter weaves the social, scientific and biochemical aspects of beriberi into a compelling story. Susan E. Lederer is in the Section of the History of Medicine, Yale University School of Medicine, New Haven, Connecticut 06520, USA.

\section{Cultivating the power of the empire}

\author{
Nature's Government: Science, \\ Imperial Britain, and the \\ 'Improvement' of the World \\ by Richard Drayton \\ Yale University Press: 2000. 400 pp. \$40, £25

\section{Lewis Pyenson}

Today, English stands uncontested as the world's premier scientific language. This hegemony derives in part from the establishment of English-speaking institutions around the world at the time of the Industrial Revolution. Many of these institutions were concerned with exploiting nature for financial profit. In Nature's Government, Richard Drayton reviews how, beginning in the mideighteenth century, England established a large network of agricultural-improvement stations throughout its empire.
These institutions, orbiting around Kew Gardens, near London, centralized the botanical knowledge of exotic species, established protocols for moving cultivars around the world, and provided employment for hundreds of technical adepts, allowing many of them to write works on botany. Much of the money came from the public purse.

Unlike the omnibus research university, with its uncanny ability to capitalize on innovation wherever it appears, independent institutions with a particular research focus - from physic gardens and astronomical observatories to model farms and industrial testing laboratories - are perpetually threatened with superannuation. Government establishments in England that extorted profit from the soil of distant lands seem generally to have lagged behind the research front. Chemistry and then microbiology provided great promise for agriculture in the late nineteenth century; but their effects impinged on commercial botany only slowly and unevenly, as did Mendelian genetics in the twentieth century. At Kew, even biogeography and ecology seem to have found little place. Nature's Government is consequently heavy on government and light on nature. In the eighteenth century, Kew's founder Joseph Banks projected the gardens as an imperial repository for plant acculturation; his towering legacy proved hard to shake off.

Focusing on Kew, Drayton takes us from Banks, through the administration of the Hookers (William and Joseph) to the reign of William Thistleton-Dyer. The reader will discover how agricultural improvement and botany were part of a general move towards the professionalization of science in the nineteenth century. And Drayton's awkward prose informs the familiar story with new material.

It would have been good to know how all

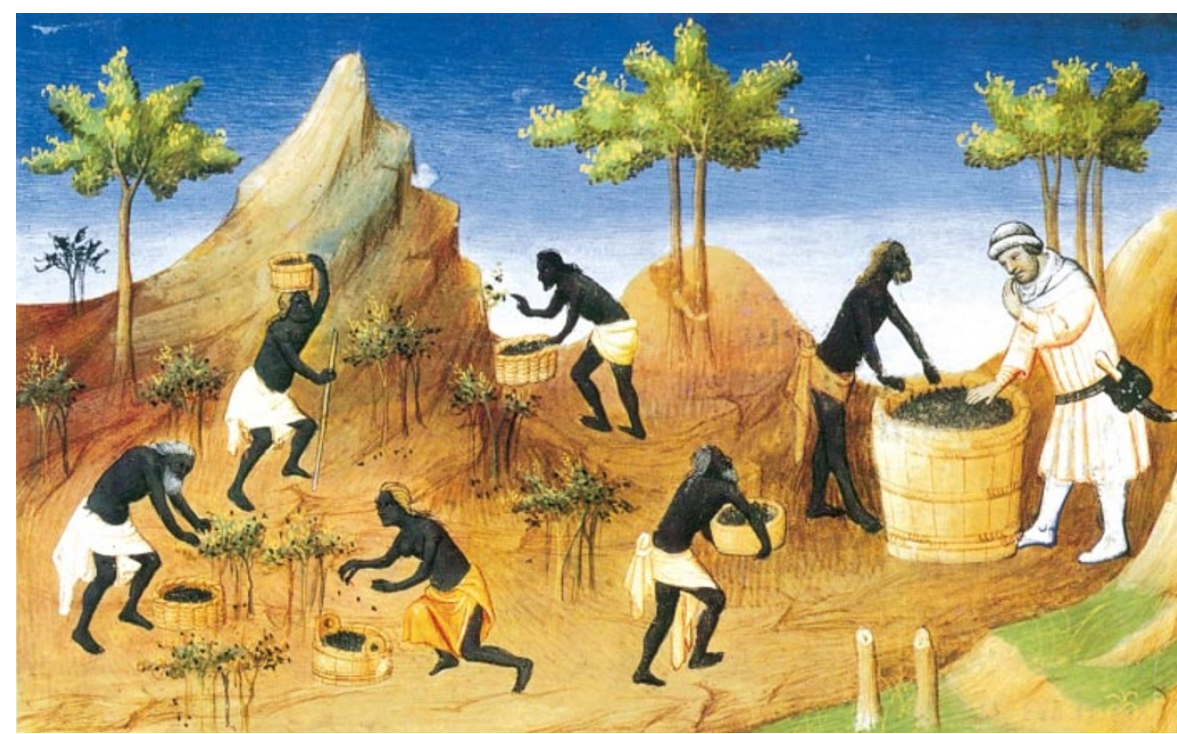

Pioneering plunder: “The Harvest of Peppers in India” from Marco Polo’s Book of Wonders. the political rhetoric was reflected in botanical publications of a putatively dispassionate kind. Did discussion about commercial value find an echo in taxonomic choices and pathogenic identification? Or did botany, secure in its disciplinary norms, master its imperial patron? The answer would tell us much about the extent to which descriptive sciences and practical technologies are embedded in the social fabric of their time and place.

Lewis Pyenson is dean of the Graduate School, University of Louisiana at Lafayette, PO Box 44610, Lafayette, Louisiana 70504-4610, USA.

\section{A warm topic for cogitation}

\section{The Hot Brain: Survival, \\ Temperature, and the \\ Human Body}

by Carl V. Gisolfi \& Francisco Mora MIT Press: 2000.272 pp. $\$ 45, £ 30.95$

\section{Andrew R. Cossins}

Mammals and birds have much larger brains than do other vertebrates. They are also different in having warm and constant body temperatures. Is this a coincidence, or is there some formal or necessary link between the two facts? Perhaps the evolutionary development of a large brain required the attainment of homeothermy? Or could it be that the brain increased in size to serve the needs of homeothermy and only subsequently became invested with increased cognitive ability? Is the further increase in brain size during hominid evolution linked to coping with heat stress? These questions are given a detailed airing in an entertaining and provocative book that explores the evolutionary and functional link between brain, warmth and thermoregulation, with an emphasis on humans.

The evolutionary development from the thermotaxic responses of basal living forms to the complex homeostatic physiology found in mammals is given detailed treatment. And there is also extensive coverage of the way in which the hypothalamic and preoptic regions of the vertebrate brain have evolved to become the main thermoregulatory control centres.

The issue of brain function and temperature affects a surprisingly large number of current issues in medicine and biology, and these liven up the book. For example, the acclimatization of humans to cold is explained within the context of the ama women divers of Korea and Japan who, before the advent of protective suits, acclimatized their bodies to the cold winter waters in which they dived. Evidence from studies in lower vertebrates suggesting that fever is adaptive and beneficial leads to the 
question of whether it should be clinically relieved with aspirin. And does the loss of thermoregulatory control during REM sleep offer any insights into how human brains can be cooled without damage?

The book is entertainingly written, and touches on many issues of general interest. It would certainly capture the attention of biologists and medical practitioners, although, given the detailed accounts of neuronal structures, I doubt that it would be accessible to non-life scientists, despite the authors' intentions. Issues in human neuroscience are authoritatively covered, but the more comparative discussions of thermal biology and the evolution of homeothermy in mammals are less convincing. For example, the idea that vertebrate brains must be warm in order to function effectively does not accord with fish that live in cold, even polar, waters. Indeed, fish can display quite sophisticated thermoregulatory behaviour, as was shown more than 30 years ago, when goldfish trained to control water heaters by leverpressing were able to regulate the temperature to within $1^{\circ} \mathrm{C}$.

Andrew R. Cossins is at the School of Biological Sciences, University of Liverpool, Derby Building, Liverpool L69 3BX, UK.

\section{Catch as catch can?}

Fish, Markets, and Fishermen: The Economics of Overfishing

by Suzanne Iudicello, Michael Weber \& Robert Wieland

Earthscan/Island Press: 1999. 192 pp.

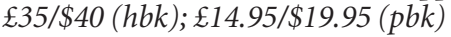

\section{John Godfrey}

Fish in the open sea are a resource common to all, but it does not pay any individual fisherman to hold back from overexploiting it. Indeed, if fish are becoming scarce, then fishing harder will often be the optimum shortterm strategy. It is rational to overfish; this is 'the tragedy of the commons'. What is needed, if we are to avoid the tragedy, is common management, fairly enforced, so that the maximum yield that each population of fish can sustain indefinitely is never exceeded.

How to do this is far from obvious. Fishing policies of governments around the world have responded to pressure from fishermen, often to the detriment of the longer term. Overfishing brings short supply and high prices, to the disadvantage of the poor, for whom fish has historically been a source of cheap first-class protein. But consumers have little influence on policies, because their interest in conservation lacks the immediate impact that policies have on fishermen, and because they lack detailed knowledge. Their

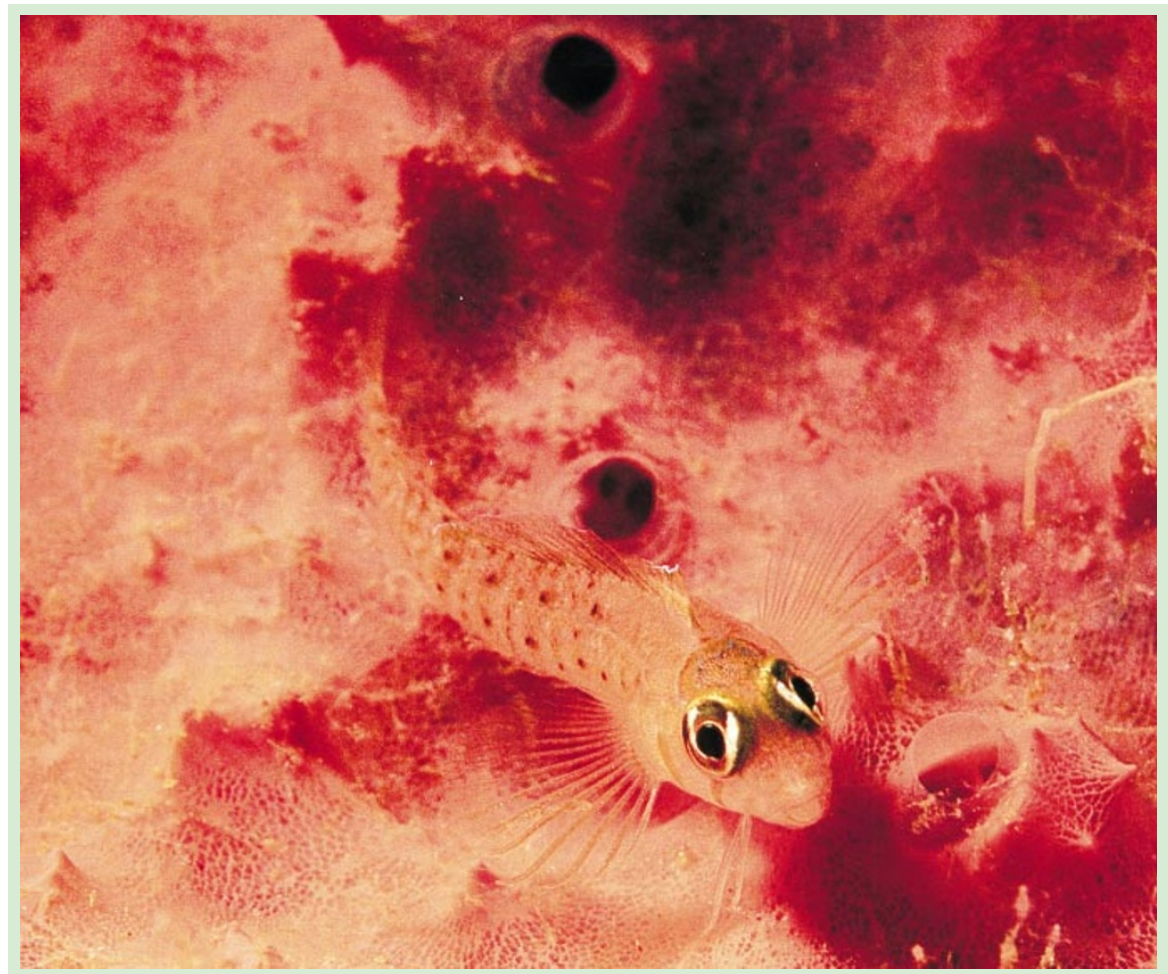

\section{Views of an underworld}

The three oceans that surround New Zealand are home to a vast array of exotic marine life, including the Yaldwyn's triplefin (Notoclinops yaldwyni) show above, resting on pink sponge.
Underwater Wonders of New Zealand by Gillian and Darryl Torckler (New Holland, $\mathfrak{E} 19.99$, $\$ 32.95)$ is a lavishly illustrated guide to this underworld. need, in both the short and long term, is sustainable management. The catching industry shares the same goal, but only in the long term.

Iudicello et al. bring a breath of fresh air to the often-stale fish dispute. They show how the exploitation of a new fish stock goes through clear phases: as the effort put into catching the fish increases steadily, the value of the catch grows quickly until the maximum economic yield is reached. There is then the greatest difference between the cost of fishing and the value of the catch. After this, profits fall off until fishing reduces the capacity of the stock to replenish itself. Beyond this, the population will fall and may crash. Policies for fishing should keep fish populations between the maximum economic and the maximum biological yield that can be sustained.

The book goes on to review examples of different management policies for various fish stocks around the world. Most have failed, often because governments give subsidies when fishing communities suffer as fishing becomes uneconomic. This lures back fishermen who might have left a depleted and uneconomic fishery.

The authors shy away from clear recommendations. But their valuable case studies suggest that somehow making fishing private property could be the answer. New Zealand has given individual quotas for fish catches that can then be traded. But the tendency then is for the quotas to be bought up by a few big enterprises. Fishing has historically been a small-scale industry, with the benefits of fishing dispersed among communities with few alternative economic possibilities. If individual quotas were to revert to a regional management body, this difficulty could be avoided and the public interest taken into account.

Because the most productive waters are often fairly near to shore, the universal adoption of 200-mile Exclusive Economic Zones made rational and legally enforceable management possible. The European Union has pooled its EEZs, and although its common fisheries policy ought to be the most successful policy for Europe, it is not. For instance, one year's better recruitment to the cod stocks in the North Sea triggered a larger total allowable catch. The young cohort should instead have been allowed to grow and breed. But the Norwegians, not being members of the European Union and therefore unhampered by the common fisheries policy, have achieved a remarkable recovery of their overexploited cod. Another aspect is the fact that the water in the North Sea has become warmer, and less favourable to breeding by cod, so that greater care in management is needed.

The main failures of management have 